Article

\title{
Fostering Sustainability Transitions by Designing for the Convergence of Policy Windows and Transition Arenas
}

\author{
John Harlow ${ }^{1, *}$, Erik Johnston ${ }^{1}$, Eric Hekler ${ }^{2}$ and Zoë Yeh ${ }^{2}$ \\ 1 School for the Future of Innovation in Society, Arizona State University, Tempe, AZ 85287-5603, USA; \\ erik.johnston@asu.edu \\ 2 School of Nutrition and Health Promotion, Arizona State University, Phoenix, AZ 85004-0698, USA; \\ eric.hekler@asu.edu (E.H.); zoe.yeh@asu.edu (Z.Y.) \\ * Correspondence: john.harlow@asu.edu; Tel.: +1-480-217-6333
}

Received: 27 July 2018; Accepted: 16 August 2018; Published: 21 August 2018

Abstract: Transition arenas that do not converge with policy windows to achieve structural or institutional change often fail to achieve their stated transformative goals. For their part, policy windows often lead to only incremental change. On their own, transition management and the multiple streams approach seem inadequate to the challenges facing cities. However, in combination, they can be transformative, as exemplified by the Citizens Committee for the Future of Phoenix Transportation. In 2015, this committee in Phoenix, AZ passed a USD 31.5 billion 2050 transportation plan funded by a sales tax increase from 0.4 to $0.7 \%$. This plan's development realized a policy window in a transition arena through an instrumental boundary object workshop with innovative facilitation. This article sets out to explore, based on this in-depth, applied transition arena process, how to combine transition management and the multiple streams approach to increase the transformative potential of transition arenas. The multiple streams approach and transition management have rarely been used simultaneously or had their integration planned. However, this case from Phoenix, $\mathrm{AZ}$ illustrates the potential for boundary objects and facilitation processes in designing for the convergence of policy windows and transition arenas.

Keywords: transition management; transition arena; multiple streams approach; policy window; boundary object

\section{Introduction}

Transition arenas [1-3] that do not converge with policy windows [4,5] have largely failed to achieve their stated goals, i.e., "the aspired large scale systemic changes" [2] (p. 63). A policy window occurs when the three streams of Kingdon's multiple streams approach (MSA) [4] flow together. Those streams are (1) problems perceived by political actors, (2) policies acceptable in the current discourse and implementable given available resources, and (3) politics aligning the interests of the public or powerful actors with a problem and policy. In this approach, policy entrepreneurs only succeed in policy making when they have the resources, access, and strategies appropriate for joining the streams and developing policy [5].

Kingdon and Thurber first developed the MSA in 1984 and, in the years since, that work has been cited over 12,000 times and applied to 22 policy areas in 65 countries [5]. However, policy windows are typically seen as an opportunity of circumstance, rather than intentionally created. Thus, methods for creating policy windows are lacking [6], partially because the MSA has thus far been primarily applied as a post hoc policy analysis tool, rather than a policy development tool. 
Cities, of course, face a host of challenges ripe for policy development. Unfortunately, because "topdown planning and market-based strategies are insufficient to deliver fundamental and accelerated changes that are needed" [7] (p. 67), the policies delivered through policy windows tend to be reactive, short-term responses to specific challenges instead of considerate of overall systems and their dynamics. Rather than defining problems, visioning long-term futures, and backcasting, policy windows react to the present, sometimes turning today's solutions into the problems of tomorrow.

Repeatedly and predictably, this approach leads to unintended consequences. For example, existing land use has negative impacts on public health [8]. Similarly, automobile infrastructure has been prioritized [9] above alternatives that improve health [10] and reduce emissions [11], such as walking, biking, and transit development. Developers (i.e., members of the economic elite) have more influence over policy, and thereby development often prioritizes developers over other publics [12]. Further, preoccupation with economic development has marginalized concerns about social justice and/or social services [13]. Finally, urban environmental challenges manifest in many systems, such as storm-water management [14], uneven tree canopy cover [15], and poor air quality [16], among others.

Over the past 17 years, transition management $[1,2,17]$ has been developed as a potential alternative to reactive, short-term policy-making. Transition management arose around a national energy transition in the Netherlands [18], but has been applied increasingly at the urban scale [17], and seeks to: "better understand large scale systemic change in societal systems and explore possibilities for influencing the speed and direction of change in these systems" [2] (p. 49). It has been employed for reducing the emissions of Dutch energy production [19], shifting the burden of Belgian waste management to producers [20], and urban redevelopment in Rotterdam's City Ports area [21].

This article will enlist five main concepts from the transitions literature. First, (1) transitions are "the result of co-evolving processes in economy, society, ecology, and technology that progressively build up toward a revolutionary systemic change on the very long term" [2] (p. 49). To guide that progress toward systemic change requires (2) transition management to "utilise existing dynamics and orient these dynamics to transition goals that are chosen by society" [19] (p. 15). The abstract and theoretical foundation from which transition management was derived is (3) transition governance [2]. The actors who "initiate and guide a transition management process" [3] (p. 135) are the (4) transition team, who invite and facilitate participants in (5) transition arenas: "actual initial incubators of change ... crewed by local frontrunners that are considered as engaged visionary people with diverse backgrounds" [22] (p. 111).

The transitions literature presents the field as parallel and complementary to conventional policy processes; for example "a transition arena starts in the shadow of the regular policy, only increasing interaction with regular policy when ideas mature" [23] (p. 379) and "Rotmans et al., had defined transition management as complementing existing policy with a long-term vision" [24] (pp. 403-404). Thus far, articulations of transition management have appealed to academics in the literature, but have struggled to translate from theory to practice [2]. This lack of impact may be related to an explicit divergence from policy-based approaches: "instead of starting from a policy or market-based approach, transition management starts from the conceptualization of persistent challenges as embedded in the dominant regimes in complex societal systems" [2] (p. 62). However, there is potential for the transition management to better integrate with policy development; in particular, transition arenas are natural venues for creating the MSA's policy windows.

The MSA has been called "a generally self-contained literature, populated primarily by isolated case studies" [5] (p. 49). Thereby, scholarship on the MSA and transitions has primarily happened separately and in parallel. However, a Google scholar search for "transition arena" and "policy window" does return 14 results at the time of writing. Of these 14 results, seven were duplicates, working papers, not available in English, or did not actually include those specific search terms in the body of the work. The list below examines how the remaining seven results (five peer reviewed journal articles, one whitepaper, and one report) engage the potential intersection of transitions and the MSA. 
1. The first journal article explicitly articulates that transition arenas can host MSA streams: "The context in which actors from all three streams develop a joint perception of problems and solutions may be termed 'transition arenas'" [25] (p. 298). However, Nooteboom and Tesiman's 2003 article primarily concerns the role of impact assessments in sustainable development.

2. The second article explores "daring decision-making" with policy entrepreneurs as individual actors in transition arenas [26]. Scholten's 2009 article is specific to the municipal administrators who mediate between public processes and transition arenas.

3. In 2013, Paredis and Block used the MSA for post hoc analysis of Dutch transition management of environmental policy in their whitepaper, stating that "the current understanding of how transition management works in practice and how it influences regular policies is far from adequate" [27] (p. 22).

4. Bettini and Head's 2016 report [28] primarily focuses on governance of "water sensitive cities," and the transitions material is mainly confined to a Rotterdam case study in an appendix.

5. MacRae and Winfield's 2016 article attempts "to unify disparate literatures pertinent to the food policy change process in Canada" [29] (p. 141), with transitions and policy windows two among many referenced literatures. However, the transitions approach is only found to be applicable to one of their four cases, and the intersection of transitions and policy windows is not a major focus of their framework.

6. The MSA appears in only one paragraph of the conclusion of Van Poeck et al.'s 2017 article [30] on sustainability change agents, and is not integrated with any discussions of transitions.

7. Like Paredis and Block [27], Noboa and Upham [31] directly connect transitions and the MSA in their 2018 article. They focus on transition management for energy policy in illiberal democracies, propose that transition arenas include policy entrepreneurs, and identify transition arenas as a venue to host the joining of the MSA streams.

Building on these few touchpoints between the transition management and MSA literatures, this article explores the potential of the MSA to be a vehicle of strategic engagement between transition management and conventional policy processes. Nooteboom and Tesiman [25] note that transition arenas can offer a setting in which the MSA streams can be joined, Scholten [26] suggests that transition arenas can benefit from the inclusion of policy entrepreneurs, and Noboa and Upham [31] draw both these insights into their illiberal democracy context. The research question of this article then emerges from the work done by Paredis and Block [27], by also using the MSA for post hoc analysis of transition activities. That research question is: How might the integration of the MSA with transition management offer new opportunities for transition activities to interface with conventional policy processes?

One possible method of integrating the MSA with transition management is the creation of a boundary object: "objects which are plastic enough to adapt to local needs and the constraints of several parties employing them, yet robust enough to maintain a common identity" [32] (p. 393). Boundary objects have interpretive flexibility, meaning they can be interpreted in different ways through different perspectives. This quality makes boundary objects conducive settings for "different groups to work together without consensus" [33] (p. 602). This article presents a case example from Phoenix, AZ, in which a prioritization workshop (boundary object) for the Citizens Committee on the Future of Phoenix Transportation (CCFPT) (transition arena) facilitated the coupling of the MSA streams. This innovative budgetary decision-making workshop realized a policy window in support of a transportation transition from 2015 to 2050.

The remainder of the article is structured as follows: We introduce the CCFPT and describe the materials and methods of the boundary object workshop, present the results of that workshop, and then discuss the CCFPT in the context of both the MSA and transitions. The article concludes with thoughts about the overlap of the approaches and potential future research on designing for the convergence of transition arenas and policy windows. 


\section{Background}

Transitions are transformational change on generational timescales, and Phoenix has been experiencing a transition in its transportation system for decades. In 1985, Maricopa County voters approved a $0.5 \%$ sales tax to fund freeway and transit expansion (Valley Metro, 2016). In 2000, City of Phoenix voters passed the Transit 2000 Regional Transportation Plan (T2000), with a $0.4 \%$ sales tax to supplement funding for bus, light rail, and other transit. These two taxes were indications that "co-evolving processes in economy, society, ecology, and technology" [2] (p. 49) were converging on revolutionary systemic change: the first high capacity urban transit in the region. With voters making their economic priorities known, in 2008, Valley Metro constructed a regional light rail line with the potential to reduce traffic and automobile pollution in Phoenix [34].

The T2000 sales tax was scheduled to expire in 2020, which would have reduced light rail, bus, and other transit services in Phoenix by up to $60 \%$ [35]. To prevent this extreme service disruption, Mayor Greg Stanton and Phoenix's City Council established the CCFPT in 2014. This committee included a wide variety of Phoenix organizations and constituencies, ranging from large businesses to mission-driven transit organizations, a libertarian think tank, and service providers for the homeless.

The people assembled in the CCFPT brought significant knowledge to the process from their diverse personal and professional experience, including capacity in economics, labor union organization, real estate development, transportation advocacy, and long-term residency in Phoenix, among many other knowledge domains. Because the CCFPT worked with the authors as transitions experts, we considered the committee a transition arena oriented to a policy approach. In the MSA, the CCFPT members and the City of Phoenix staff facilitating the committee could be considered policy entrepreneurs. Committee meetings began in August of 2014, with the powers and duties to:

- Evaluate transit and street transportation needs.

- Obtain citizen input through a variety of public engagement methods.

- Provide interim reports to the Citizens Transit Commission and Transportation and Infrastructure Subcommittee on Committee progress.

- Develop a draft transportation plan that includes a funding strategy.

- Present a recommendation to the Mayor and Council on the future of transportation in Phoenix [36].

In August of 2014, the authors met with the Phoenix Public Transit Department (PTD), and after a series of meetings and discussions, agreed to assist with online public engagement, orient two graduate courses toward the development of the transportation plan, and to provide research support to Public Transit staff tasked with responding to queries from CCFPT members. The authors attended CCFPT meetings, observed the process, and developed relationships with CCFPT members and the City of Phoenix staff who designed and facilitated the meetings. The authors perceived their involvement to be tantamount to the creation of a transition team for Phoenix's transportation transition, with the CCFPT a transition arena with clear opportunity to host a policy window and create a "transition agenda" [3] (i.e., the transportation plan). However, to avoid things being "made more complicated through the layering of transition management reforms" [24] (p. 403) and having to orient and educate unfamiliar participants, this framing was not imposed on the CCFPT or city staff.

Over the course of the CCFPT meetings, the expected time horizon of the transportation plan, and thereby of the transportation transition, crystallized, moving from 20 years out [37] to 2050 [38]. The long-term visioning in CCFPT meetings had consisted primarily of presentations by City of Phoenix staff detailing demographic, economic, and development trends from the present until 2050. However, some committee members felt that progress toward development of the actual plan was slow. To address this, the CCFPT requested a supplemental workshop to prioritize the potential transportation plan elements that had been presented to them [39]. Because this prioritization workshop request was emergent, PTD staff did not have a plan in place for such an event. Given the authors' ongoing involvement with the CCFPT, we offered to design the workshop, which we 
perceived to be a boundary object that could function as the decision style of the MSA. In the spirit of inclusive public management [40], our offer was welcomed, and a rapid iterative design process began. The workshop was planned for approximately three weeks from when it was proposed, spurring a flurry of prototypes from the authors, and ongoing feedback from city staff.

\section{Materials and Methods}

\subsection{Priortization Workshop Design}

The prioritization workshop drew design guidelines from human-centered design [41], agile science [42], and boundary objects [33]. The process included sketching and paper prototyping [43], physical prototyping, participatory design [44] with City of Phoenix staff, and iterative testing and improvements of the orientation, facilitation, and materials. To begin the design process, PTD staff recommended that the authors review a digital transportation survey. This manifested as a "playing card" survey visualizing a diversity of transportation priorities and assigning them rough numbers. Field tests of that survey had generated anecdotal satisfaction with the process of using the cards to describe desires for transit, so it was adopted and iterated for the prioritization workshop.

The next iteration moved from the "playing card" format to square "pieces" sized in proportion to their projected cost; e.g., new light rail lines were large pieces, whereas installing shade at all bus stops was a small piece. Those pieces would begin on a large "board" with the same proportion, which thereby represented the running cost of a transportation plan. The reasoning behind these choices was that sizing the boards and pieces in proportion to their costs helped to "provide open access to useful data and tools in usable formats" [45] (p. 206), and enabled easy processing of the relative costs of transportation options, because tactile pieces represented that relationship. Similarly, the discrete nature of each piece made discussion of each plan element salient for the CCFPT [46].

The authors suggested that workshop attendees be divided into groups of six or less to offer individuals more chances to participate verbally than attempting the exercise with the entire group of 35. The process of negotiating each piece in turn, in small groups, allowed participants ample opportunities to express their perspectives on which "vision elements" [3] should be in the plan, as well as offer rationale for those perspectives when questioned by other committee members. Lastly, beginning with all of the pieces on the board communicated the transit priorities recommended by City of Phoenix staff.

\subsubsection{Prototype 1}

The goal for Prototype 1 was to communicate the workshop idea to City of Phoenix staff and test its viability for the CCFPT. Prototype 1 was a sheet of $8.5^{\prime \prime}$ by $11^{\prime \prime}$ paper, cut into differing sizes, with titles of transportation options and made up costs. The pieces were then placed on an uncut $8.5^{\prime \prime}$ by 11" piece of paper representing a board. Maria Hyatt, Director of Phoenix's Public Transit Department, found the concept intriguing, and scheduled a presentation of it at the next CCFPT meeting.

\subsubsection{Prototype 2}

The goal for Prototype 2 was to communicate the activity at the next CCFPT meeting and receive authorization to pursue this model for the prioritization workshop. PTD staff printed large pieces that were color-coded to differentiate between categories (e.g., bus, light rail, streets) with "back of the envelope" cost projections. Despite the "board game" (as the committee termed it) being unfamiliar to their experience, it was approved. The authors then offered to train the facilitators from City of Phoenix staff who would lead groups through the workshop, and began preparing a new prototype.

\subsubsection{Prototype 3}

The goals for Prototype 3 were to: (1) train the facilitators; (2) test the facilitation guide; and, (3) review the materials for accuracy and effectiveness at intended communication. To develop 
Prototype 3, PTD staff translated all potential transportation investments that had been presented to the CCFPT into an investment table with explanations and projected costs (Appendix A). Each line item in the table was discussed to make sure that it would be easily understood by the CCFPT, and that only the most logical options were included, to limit the cognitive complexity of the decision-making process and avoid "choice paralysis" [47]. Each line item then became a piece, displaying a transportation option's title, cost, and visualization on the front, and a justification on the back (Figure 1).

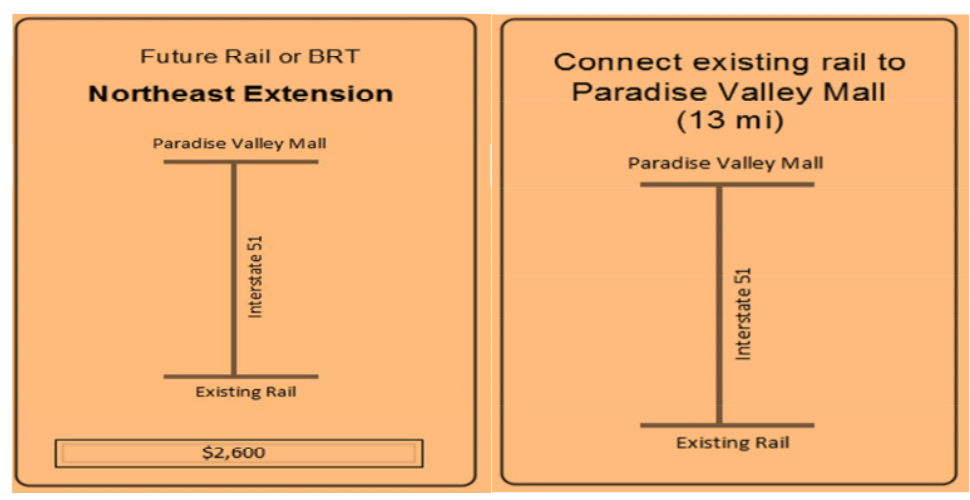

Figure 1. Example front and back of a "piece".

For the two-hour facilitator training, Prototype 3 included a full set of pieces and boards. The boards represented different size plans, ranging from USD 25-40 billion. The largest board was used to scale the proportionality, with 36 " by $48^{\prime \prime}$ (the largest size to easily print) representing the maximum cost ( USD 40 billion) of the transportation plan if all investments recommended by PTD staff were included. This made each square inch of the board equivalent to USD 23 million.

During setup for the training, the initial idea of having participants replace their boards for differing total budgets was immediately challenged by the facilitators. Also, the correspondence between the facilitation guide and the investment table was insufficient for facilitators new to the materials. Lastly, some of the pieces were improperly sized, and many graphics were missing.

\subsubsection{Prototype 4-The Final Product}

Prototype 4 was the final version, and evolved from Prototype 3 based on the recommendations from the facilitator training and testing with the participating graduate classes. An alternative board design divided the boards into USD 5 billion increments, rather than replacing boards for differing total budgets. The facilitation guide was revised to better account for CCFPT members' unfamiliarity with the activity and offered groups time to ask their respective facilitators clarifying questions, review the process, and establish the expected product: A draft transportation plan (transition agenda) represented by a photograph of the board with their selected pieces. The facilitation guide was color-coded and organized to match the investment table, which helped facilitators stay on track and easily reference between the guide and table. City of Phoenix staff reviewed, corrected, and finalized all piece and board text and visuals, proofed the investment table to make sure all projections were correct, and printed and laminated final materials. Table 1 collects each step of the prototyping process. 
Table 1. Prototyping process steps.

\begin{tabular}{ccccc}
\hline Prototype & Materials & Goals & Feedback & Resulting Changes \\
\hline 1 & $\begin{array}{c}\text { Cut up } 8.5^{\prime \prime} \times 11^{\prime \prime} \\
\text { paper and pen }\end{array}$ & $\begin{array}{c}\text { Explanation to staff and } \\
\text { opportunity to present } \\
\text { to CCFPT }\end{array}$ & $\begin{array}{c}\text { Prepare for CCFPT } \\
\text { presentation }\end{array}$ & $\begin{array}{c}\text { Color coding and } \\
\text { rough cost projections }\end{array}$ \\
\hline 2 & $\begin{array}{c}\text { Large color-coded } \\
\text { pieces of different sizes } \\
\text { printed with costs } \\
\text { and visuals }\end{array}$ & $\begin{array}{c}\text { Explanation to CCFPT and } \\
\text { authorization to implement }\end{array}$ & $\begin{array}{c}\text { Prepare to deploy } \\
\text { the activity }\end{array}$ & $\begin{array}{c}\text { Cost table, sets of } \\
\text { pieces, boards, and } \\
\text { facilitation guide }\end{array}$ \\
\hline 3 & $\begin{array}{c}36^{\prime \prime} \times 48^{\prime \prime} \text { boards and } \\
\text { a full set of pieces }\end{array}$ & $\begin{array}{c}\text { Train facilitators, test the } \\
\text { guide, and review materials }\end{array}$ & $\begin{array}{c}\text { Guide did not match } \\
\text { sheet, print totals on } \\
\text { one board }\end{array}$ & $\begin{array}{c}\text { Guide matched to } \\
\text { sheet, board redesign, } \\
\text { typos and } \\
\text { sizing corrected }\end{array}$ \\
\hline 4 & $\begin{array}{c}\text { Five } 36^{\prime \prime} \times 48^{\prime \prime} \text { boards } \\
\text { and five full sets of } \\
\text { accurate pieces with } \\
\text { costs, visuals, } \\
\text { and justifications }\end{array}$ & $\begin{array}{c}\text { Satisfied CCFPT; empathy } \\
\text { with the public and each } \\
\text { other; accessibility of data } \\
\text { and staff expertise; sufficient } \\
\text { opportunities to express and } \\
\text { explain ideas }\end{array}$ & $\begin{array}{c}\text { Audio coding, and } \\
\text { process satisfaction } \\
\text { survey results }\end{array}$ & NA \\
\hline
\end{tabular}

\subsection{Prioritization Workshop Evaluation}

During the 22 November 2014 prioritization workshop, audio was recorded for four of five groups of CCFPT members, with one not available due to technical difficulties. The research team reviewed the audio recordings using a thematic analysis approach [48] to derive a list of potential coding elements. Final codes were based on intentions for the workshop activity and the prevalence of the interactions the activities were designed to encourage.

Three coders from Arizona State University's Center for Policy Informatics were recruited to listen to and code the audio recordings. The team went through an iterative process for establishing the veracity of the coding strategy and final codes for all audio recordings. The first round clearly defined the codes using a sub-set of the audio recordings. This was done to establish conceptual agreement among all the coders. The final definitions for the four codes were as follows:

- "Empathy" was coded when CCFPT members expressed empathy with the public; for example: "People who ride the bus need to get to work".

- "Rationale" was coded when CCFPT members offered a rationale for the inclusion or removal of a plan element; for example: "That costs too much, we should take it out".

- "Data" was coded when the data available to CCFPT members was leveraged to make decisions; for example: "The map shows high population growth there".

- "Staff" was coded when the attending city staff answered questions beyond the data available to CCFPT members; for example: "What federal fund would potentially be available to pursue this transit expansion?".

With codes established, all audio recordings were double, and at times triple, coded by separate coders. After all audio files were at least double coded, the coding team met repeatedly to discuss discrepancies, until a final, mutually agreed-upon coding was established for all recording segments.

\section{Results}

The boundary object workshop hosted 24 of the 35 CCFPT members broken into five teams facilitated by City of Phoenix staff (e.g., Figure 2). Each table hosted a map projecting future employment and residential density in the city, and showing the path for all potential new high capacity transit (i.e., bus rapid transit, streetcar, and light rail) investments, as well as a copy of the "Transit Book", which provided any desired supplementary statistics about Phoenix transportation. CCFPT members had the investment table detailing each potential plan element, its projected 
cost, and the reasoning behind its inclusion (e.g., sixth-highest ridership bus route in the city). The information in the investment table was also translated onto the pieces, which listed the projected cost numerically, and represented it with the size of the piece. The front of each piece also included a visual to help make the investment accessible to participants and easily locatable on each table's map. The back of each piece similarly corresponded to the investment table, listing the rationale for each element's inclusion in the table. Finally, the surface area of the board represented the total cost of the plan, and was divided into $\$ 5$ billion slices for easy reference to a running total during the activity.

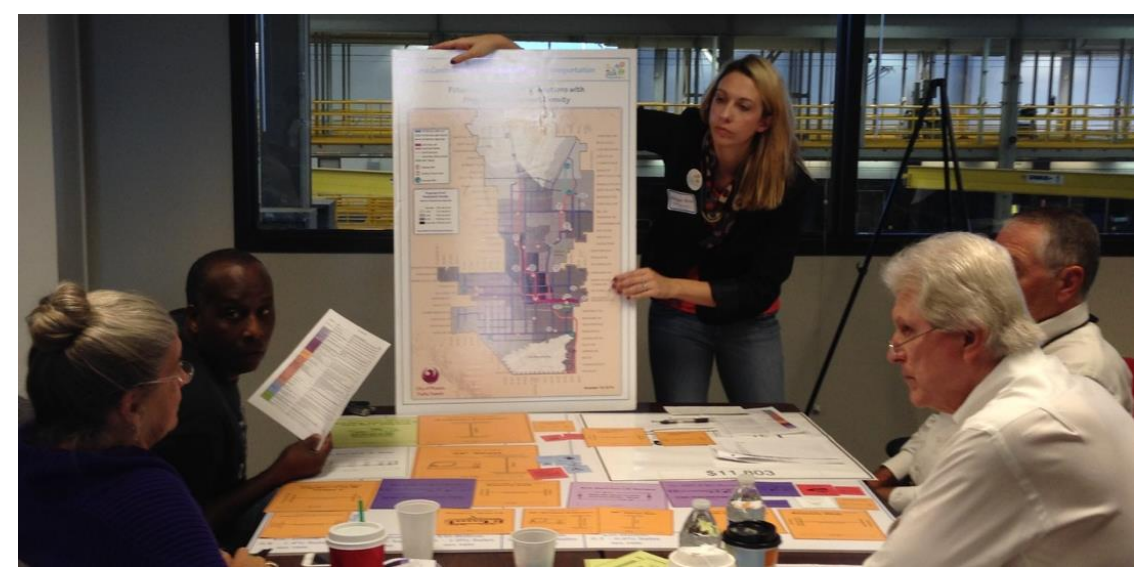

Figure 2. City of Phoenix staff facilitating CCFPT members.

The CCFPT members were oriented to the activity, including the intention of PTD staff to integrate the draft transportation plans produced at each table into a single plan for refinement in subsequent CCFPT meetings. Participating committee members then had the chance to ask clarifying questions before negotiating which transportation options they wanted in their draft plan. From the transitions perspectives, these negotiations were about which vision elements to include in the transportation agenda. At the end of the allotted three hours, all five groups had completed the activity. Some groups signed their completed game boards at the completion of the exercise (Figure 3). After the workshop, city staff analyzed the photographs to determine which elements were in every group's plan, which were in no group's plan, and which should receive further attention. The elements in every group's plan were presented as the baseline plan, and subsequent CCFPT meetings determined whether the transportation plan options in some groups' plans made it into the final plan. The final plan went through a transportation and infrastructure subcommittee, Phoenix City Council, and to voters on 25 August 2015, when it was passed.

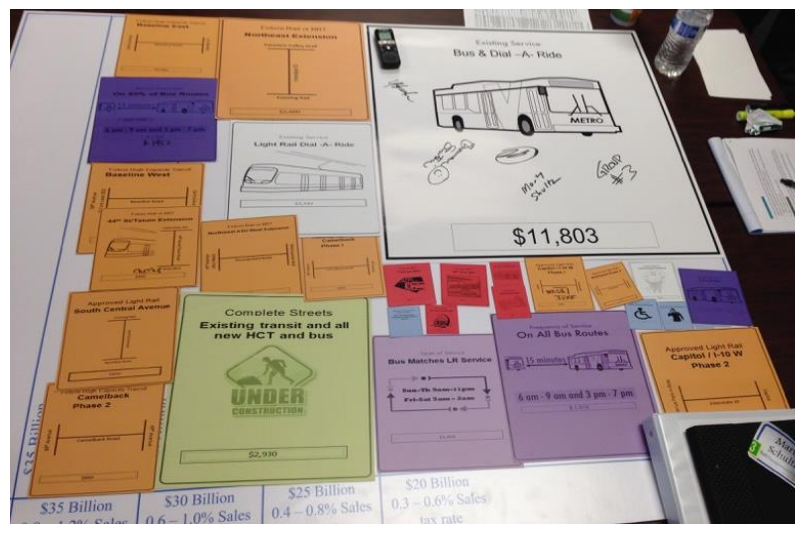

Figure 3. Example completed "game board". 
Audio analysis was conducted on the four groups for which audio was recorded (Table 2). "Total Time" refers to the time between the first coded statement and the last because all four recordings included clarifying preamble and some post mortem about the process. While analyzing the audio to code types of interaction, it was often the case that discussion simultaneously included multiple codes; for example, whenever a CCFPT member used available data to provide rationale for a choice. As such, the sum of coded minutes across topics (and thus also percentage of time) exceeds the time spent. Time was quantified by assigning each coded instance a value of one minute.

Table 2. Time per coded topic.

\begin{tabular}{cccccccccc}
\hline & \multicolumn{2}{c}{ Empathy with Publics } & \multicolumn{2}{c}{$\begin{array}{c}\text { Rationale for Plan } \\
\text { Priorities }\end{array}$} & \multicolumn{2}{c}{ Use of Available Data } & Use of Staff Expertise & $\begin{array}{c}\text { Total } \\
\text { Time }\end{array}$ \\
\cline { 2 - 11 } & $\begin{array}{c}\text { \% Time } \\
\text { on Topic }\end{array}$ & $\begin{array}{c}\text { Min on } \\
\text { Topic }\end{array}$ & $\begin{array}{c}\text { \% Time } \\
\text { on Topic }\end{array}$ & $\begin{array}{c}\text { Min on } \\
\text { Topic }\end{array}$ & $\begin{array}{c}\text { \% Time } \\
\text { on Topic }\end{array}$ & $\begin{array}{c}\text { Min on } \\
\text { Topic }\end{array}$ & $\begin{array}{c}\text { \% Time } \\
\text { on Topic }\end{array}$ & $\begin{array}{c}\text { Min on } \\
\text { Topic }\end{array}$ & Min \\
\hline Group & & & & & & & & & \\
1 & $9.3 \%$ & 7.1 & $62.4 \%$ & 47.4 & $32.2 \%$ & 24.5 & $22.9 \%$ & 17.4 & 76 \\
2 & $19.4 \%$ & 16.7 & $94.9 \%$ & 81.6 & $11.4 \%$ & 9.8 & $17.8 \%$ & 15.3 & 86 \\
3 & $8.7 \%$ & 9.4 & $64.3 \%$ & 69.4 & $6.2 \%$ & 6.7 & $10.3 \%$ & 11.1 & 108 \\
4 & $15.6 \%$ & 18.1 & $54.0 \%$ & 62.6 & $20.4 \%$ & 23.7 & $10.7 \%$ & 12.4 & 116 \\
\hline Avg & $13.3 \%$ & 12.8 & $68.9 \%$ & 65.3 & $17.6 \%$ & 16.2 & $15.4 \%$ & 14.1 & 96.5 \\
\hline
\end{tabular}

Beyond coding the interactions between CCFPT members during the workshop, PTD staff also distributed a process satisfaction survey to CCFPT members who participated. Of the 24 attendees, nine completed the short survey (Table 3). Results from this survey indicated that respondents were generally satisfied with the workshop, and that six of the nine respondents believed that the workshop changed participating CCFPT members' opinions about transportation.

Table 3. Prioritization workshop satisfaction.

\begin{tabular}{|c|c|c|c|c|c|c|}
\hline & & $\begin{array}{c}\text { Very } \\
\text { Dissatisfied }\end{array}$ & $\begin{array}{l}\text { Somewhat } \\
\text { Dissatisfied }\end{array}$ & Neutral & $\begin{array}{l}\text { Somewhat } \\
\text { Satisfied }\end{array}$ & $\begin{array}{c}\text { Very } \\
\text { Satisfied }\end{array}$ \\
\hline \multicolumn{2}{|c|}{$\begin{array}{l}\text { Overall, how satisfied were you with the Saturday, } \\
\text { November 22nd prioritization workshop? }\end{array}$} & & 1 & 1 & & 7 \\
\hline \multirow{6}{*}{$\begin{array}{l}\text { Specifically, how } \\
\text { satisfied were you with } \\
\text { the Saturday November } \\
\text { 22nd prioritization } \\
\text { workshop: }\end{array}$} & Activity & & 1 & 1 & & 7 \\
\hline & Facilitation & & & 2 & 2 & 5 \\
\hline & Availability of data & & 2 & & 4 & 3 \\
\hline & $\begin{array}{l}\text { Availability of } \\
\text { relevant staff }\end{array}$ & & & & 2 & 6 \\
\hline & $\begin{array}{l}\text { Opportunities to voice } \\
\text { your thoughts }\end{array}$ & & & & 2 & 7 \\
\hline & Final Product & 1 & & 1 & 1 & 6 \\
\hline \multicolumn{2}{|c|}{$\begin{array}{l}\text { Do you feel the conversation at the workshop } \\
\text { changed anyone's ideas about transportation? }\end{array}$} & \multicolumn{2}{|c|}{$\begin{array}{l}\text { Yes } \\
6\end{array}$} & & \multicolumn{2}{|c|}{$\begin{array}{c}\text { No } \\
3\end{array}$} \\
\hline
\end{tabular}

Quotes from the audio recordings reinforced positive perceptions of the process, in line with the results from the coding, its quantitative analysis, and the process satisfaction survey. Comments made about the process were generally supportive (e.g., "This would be great for schools ... I'll take it home and use it at home"), with less supportive comments tending to be less central to the process (e.g., "These are the tiniest pieces ever"). Comments at the conclusion of the process in all groups were positive, with statements such as: "I'm very proud", "I think we did good" and "We should have this signed and you're going to do a picture right ... let's write all of our names." These comments indicate not only satisfaction with the process, but also suggest pride and satisfaction with the plan that had been created. 


\section{Discussion}

The CCFPT exemplifies an overlap of two conceptual models of societal change: the MSA and transition management. This combination was successful partially because of an innovative boundary object workshop. The following discusses how the prioritization workshop can be categorized as a boundary object, and how the overall CCFPT process corresponds to the MSA and transitions, respectively.

\subsection{The Prioritization Workshop as a Boundary Object}

The prioritization workshop functioned as a boundary object because of "delegations of authority from principals to agents within or between organizations" [49] (p. 401), specifically the City of Phoenix delegated workshop design to the authors. Additionally, the workshop had the interpretive flexibility of a boundary object "between social worlds" [33] (p. 604) of at least three parties, in this case, the CCFPT, the mayor of Phoenix and city staff, and the authors. The committee was unsure that city staff were providing sufficient progress toward a transportation plan, and hoped the workshop would spur them forward toward their expected product. The mayor of Phoenix and the city's staff saw the workshop as a meeting space where the CCFPT would create a transportation plan (i.e., transition agenda). The authors viewed the CCFPT as a transition arena ripe for an iteratively designed decision-making workshop, in which the assembled frontrunners could have small group opportunities (unlike the full 35-member group) to express and explain their priorities. Because the CCFPT was crewed by frontrunners open to innovative ideas and facilitation, the authors were confident they would be open to the unconventional workshop design.

\subsection{The CCFPT in the Context of Transitions}

Loorbach et al. reflect on the field of transition studies by translating abstracted tenets of transition governance into a practical framework [2]. The CCFPT went through the transition management process phases $[50,51]$ in that framework as follows:

1. The mayor and Phoenix's Streets Transportation and Public Transit Departments (problem owners, content experts) and the authors as academic collaborators (transition management experts) [2] formed an informal transition team.

2. Based on City of Phoenix staff research on the state of transportation in Phoenix, and the relevant stakeholders and actors in the city, participants were invited by the mayor and Phoenix City Council to a transition arena (i.e., the CCFPT) with the city staff and academic partners who structured and facilitated the committee's process.

3. Transition teams structure problems, which in this case included unmet promises from T2000, overdue street repairs, and the expiry of transportation funding in 2020.

4. The CCFPT met repeatedly to envision a future in which Phoenix had transitioned its transportation system to a more sustainable level of high-capacity public transit, starting with T2000 light rail maps (visionary images) and negotiating potential guiding principles (transit access, budgetary responsibility, etc.).

5. The product of the CCFPT transition arena was a transition agenda in the form of a 2050 transportation plan with specific transition pathways of fundamental investments (e.g., new highcapacity transit lines, street overlays) and funding mechanisms.

6. This plan was presented to and approved by voters in a 2015 ballot initiative.

7. Subsequently the Citizens Transportation Commission was established to disperse funds, and ideally to develop transition strategies and implement transition experiments.

Loorbach et al. also lay out the theoretical basis of transition governance, suggesting that actions should coordinate with existing dynamics for incremental change, which can eventually lead to tipping points and feedback into those ongoing dynamics [2]. In the case of the CCFPT, the committee's 
actions were specifically coordinated with the existing political dynamics in Phoenix, namely, that the results of their work would be presented to the Phoenix City Council for consideration as a ballot initiative. This ballot initiative represented a $\sim$ USD 30 billion tipping point toward a transition in the transportation sector, achieved only through frontrunner effort since before 1985's county sales tax. The CCFPT's specific transportation recommendations have been fed back into ongoing city staff processes to be responsive to demographic, technological, and other unexpected changes during the plan's 2050 timeline.

To further contextualize the CCFPT case, we have also drawn on nine "tenets of transition governance" [2] (pp. 51-52). The long-term thinking tenet of transition governance (1), was inherent in the 2050 timeline of the transition agenda (transportation plan) produced, and the tenet of flexibility in system level objectives (2) was met through the ability of city staff to adapt transportation plan priorities as Phoenix changes over time. The heavy involvement of city staff also aligned with the transition governance tenet of steering from "inside" (3).

Another transition governance tenet connects process management with content (4), suggesting that understanding system dynamics is a prerequisite. For the CCFPT, understanding system dynamics took up the majority of most meetings, with staff from Phoenix's Streets Transportation and Public Transit Departments presenting budgets, statistics, and projections about Phoenix transportation [37]. Understanding systems highlights disequilibria, and one transition governance tenet asks that participants use both disequilibria and equilibria to further transitions (5). For the CCFPT, one disequilibrium was heavy flooding in Phoenix on 9 September 2014, which was discussed as a reason to orient transportation investments toward wastewater management needs [37].

Intervention timing (6) is a "crucial" tenet of transition governance. For the CCFPT, three interventions were well timed, the committee was formed with plenty of lead time (2014-2020) to develop a new plan before the previous funding mechanism expired, the ballot initiative was calibrated to the political environment (evidenced by its passing), and partnering with academics created enough resources and capacity to effectively intervene in the CCFPT meeting process. This last boundary object intervention facilitated the transition governance tenet (7) that "(social) learning about different actor perspectives and a variety of options ... is a necessary precondition for change" [2] (p. 52). This was accomplished by creating opportunities for each participant to express and explain their perspectives and rationale for each potential transportation investment, and evidenced by perceptions that committee members changed their opinions about transportation during the workshop (Table 3).

Stakeholder participation was built into the CCFPT process with "frontrunners ... city administrators, researchers, businesses, civil society organizations, and citizens" [52] (p. 58) all represented in the CCFPT transition arena. City of Phoenix staff also engaged over 3500 people in a public engagement process that was reported to the CCFPT, and informed their decision-making and perceptions of transportation priorities. The boundary object workshop also provided a platform for "reframing problems and solutions through social learning" [2] (p. 52) during negotiations about which pieces would be included in each table's transportation plan. These elements of the CCFPT process addressed the transition governance tenet of participation and interaction among stakeholders (8). The only referenced transition governance tenet unmet by the CCFPT was creating space for actors to build up alternative regimes. Particularly, alternatives to train-based high capacity transit (e.g., Uber, Lyft, and autonomous vehicles) were not built into a competitive regime, and were marginalized in the discourse, after being raised by one CCFPT member [53].

Finally, Loorbach et al. list eight guiding principles for the transitions approach. In the case of the CCFPT, inclusivity (1), democracy (2), and diversity and openness (3) were addressed through the diversity of CCFPT members, the City of Phoenix's public engagement process reaching more than 3500 people during the process [54], and the conduct of CCFPT meetings. Two principles of particular interest for the future of Phoenix transportation are speed of change (4) and regime resilience (5). Transitions happen over generations, but require many incremental actions and cycles to achieve their vision. Though the timeline specified by the CCFPT was 2050, the content of the plan included 
high capacity transit expansion on decadal timelines, as well as a suite of smaller projects without definitive deadlines. The interplay between the generational transition and the near-term pilot projects and transition experiments will happen over time, as the City of Phoenix operates under the new plan.

Regime resilience and the tendency to revert to top-down governance are prevalent in Phoenix, on display through 2018 City Council action to pause the South Central light rail extension. However, we hope that the social learning and capacity building (6) of City of Phoenix staff during the CCFPT process prepares them to work with new implementation body, the Citizen Transportation Commission, as another transition arena: one oriented toward transition experiments, evaluation of progress, and iterative innovation to achieve the transition goals articulated in T2050.

The CCFPT clearly embodied the principle of context specificity (7), incorporating the geographic boundaries of the City of Phoenix, the city's political dynamics, the existing transportation infrastructure, and future demographic projections. Empowering frontrunners (8) "with multiple resources to be better equipped to play the power games with the regime" [2] (p. 61) was a key success factor for the CCFPT. In particular, the Director of the Sustainable Communities Collaborative represented a frontrunning organization already seeking to transition Phoenix's urban development from suburban style to transit-oriented development along the existing light rail. CCFPT activities offered such stakeholders information and decision-making resources with direct influence over the regime's transportation plan. We hope that subsequent participation in policy implementation on the Citizens Transportation Commission will continue to empower frontrunners with resources to support Phoenix's ongoing transportation transition.

Overall, the CCFPT was a formal, city government appointed group, with a discrete mandate. Aspects of this are not aligned with transition management (e.g., policy focused and situated in the existing regime). Yet, 2050 is a generational timeline, and the transportation plan (transition agenda) produced by the CCFPT envisions a major future transition in Phoenix's transportation system. Further, the CCFPT process was transformative by securing upwards of USD 30 billion through a policy window to transition Phoenix's public transportation from a single linear high-capacity transit line to a network of high capacity transit serving a much greater proportion of the public and offering connectivity throughout the city. Most importantly, the presence of frontrunners in the transition arena enabled the policy development to consider options beyond simple extension of status quo funding.

\subsection{The CCFPT in the Context of the MSA}

Jones et al.'s meta-analysis [4] of the MSA details a synthetic perspective on the approach. The following uses that paper as a framework to explain how the CCFPT corresponded to the MSA, and breaks down the problem, policy, and politics streams, as well as policy entrepreneurs and windows. Jones et al. list four operational subcomponents of the MSA's problem stream: indicators, focusing events, load, and feedback. In the CCFPT case, the City of Phoenix Streets Transportation and PTD presented a host of indicators, primarily oriented to promises unkept from T2000 and projections of future mismatches between transportation options and demographic change [37]. One focusing event in the CCFPT process was the massive flooding in Phoenix on 9 September 2014 [37], but the larger focusing event was the scheduled sunset of the T2000 sales tax, leading to the establishment of the CCFPT itself by the mayor and city council. The load in this case was handled before the process, in that the particular problem of transportation rose to the top of the problem agenda and catalyzed committee formation. Finally, feedback was provided in comparative analysis of Phoenix ridership and farebox recovery with other municipal transit systems, among others [55].

The policy stream of the MSA has five subcomponents that describe the "survivability" of an idea: value acceptability, technical feasibility, resource adequacy, policy communities, and network integration [4]. In the CCFPT case, proposed alternatives to trains gained little traction, aligning with the value acceptability and technical feasibility subcomponents. One proposed alternative was a point-to-point Uber-based transportation system, which failed the value acceptability test for most committee members. Similarly, statements that autonomous vehicles were the future of transportation 
did not meet the technical feasibility survivability baseline for other committee members [38]. These ideas were not widely considered in the committee process, or present in the final plan.

On the other hand, resource adequacy was a consistent and repetitive theme for the CCFPT. Many committee meetings, and the content debated therein, revolved around whether there should be a new tax, how much revenue citizens could be asked to provide, and what transportation options were desirable under various revenue constraints. These debates took place across the represented policy communities, who voiced their specific interests (e.g., breaks for bus drivers to use restrooms, no new train funding, services under the Americans with Disabilities Act) in the CCFPT meetings, which functioned as network integration.

In the MSA, the politics stream is composed of the mood of the public, the balance of interests in play, and party ideology. Jones et al. term the mood of the public "national mood" in reference to scale at which the MSA is applied in over half the cases they analyze. For the CCFPT, we render the "national mood" as the "mood of the public", and dispense with party ideology because of its lessened relevance at the municipal scale. In the CCFPT case, the balance of interests was well represented by the committee members, and their interaction with both city staff and the elected city councilors who would eventually vote on the products of their committee process. The mood of the public was gathered by the City of Phoenix public engagement process, consisting of over 100 events engaging over 3500 people online and in person [54]. The official city public engagement efforts were augmented by students supervised by the authors, who collected quotations about transportation and displayed them with pictures of the quoted citizen at the prioritization workshop.

Policy entrepreneurs are the "frontrunners" of the MSA, and provide "the necessary dose of agency required to couple the streams and shape policy outputs" [4] (p. 16). Successful entrepreneurs rely on resources, access, and strategies. The policy entrepreneurship of the CCFPT is complicated. The primary initiator of stream coupling was Phoenix's mayor Greg Stanton, however, CCFPT members, and facilitating staff all played roles in developing the transportation plan policy. It's perhaps instructive that, in this case, multiple policy entrepreneurs with differing agendas were able to collaborate in a transition arena on a major policy that addressed a diversity of priorities.

From the perspective of resources, the political capital expended by Mayor Stanton in pursuing a new transportation plan was a critical resource leveraged for effective policy entrepreneurship. For the CCFPT members, the time they spent in meetings, in particular articulating their balance of interests, was a major resource. Access, in this case, was not a challenge, with the CCFPT appointed by the mayor and city council, and major figures in Phoenix politics and urban development on the committee. These high-level decision makers managed and participated in the policy development process, making access a platform for social learning and collaboration. The final factor for policy entrepreneurs is strategies. In this case, the strategies used by CCFPT members to express and defend their balance of interests were mediated in the design of the prioritization workshop.

Lastly, policy windows have institutional context, coupling logic, and decision style [4]. The CCFPT itself, as well as the City of Phoenix political process containing the committee were the institutional context for this case. The coupling logic differed among CCFPT members, the mayor, city council, and city staff. However, the decision style employed to draft the transportation plan was specifically aimed at negotiating the range of coupling logic, through the boundary object workshop presented in Section 2.

The MSA, though more often applied at the national scale, aptly describes the convergence of streams that produced Phoenix's T2050 transportation plan. The problems stream was informed by previously unkept transportation promises, transportation data, and demographic projections. The policies stream reviewed options, and drew in familiar, proven, reasonably priced transportation options (e.g., light rail, bus rapid transit, and matching bus and light rail service hours). Similarly, the tax mechanism previously employed to fund Phoenix transportation was tapped again to support the plan. The politics stream drew together policy entrepreneurs from a diversity of Phoenix constituencies, at the behest of the mayor and city council. Table 4 collects the MSA concepts, 
explores their correspondence to the transitions approach, and gives example(s) of how the two approaches overlapped in the case of the CCFPT. Though there is much in common, it is most interesting to consider the points of divergence (all capitalized), which capture the added value of merging these approaches.

Table 4. Correspondence between the MSA and transition management.

\begin{tabular}{|c|c|c|c|}
\hline MSA & Concept [4] & Correspondence to Transitions Approach [2] & CCFPT Example \\
\hline \multirow{4}{*}{ Problem stream } & Indicators & $\begin{array}{l}\text { Indicators are defined by transition spatial } \\
\text { boundaries, provide content knowledge, and help } \\
\text { monitor and evaluate transition progress. }\end{array}$ & $\begin{array}{l}\text { City of Phoenix staff PowerPoint } \\
\text { presentations [55] }\end{array}$ \\
\hline & Focusing events & $\begin{array}{l}\text { Focusing events are "jarring and sudden" [4] (p. 15) } \\
\text { things that help answer the question: "Why do we } \\
\text { need a transition?" [51] (p. 95). }\end{array}$ & $\begin{array}{l}\text { CCFPT formation to prevent transit service } \\
\text { loss and articulate a transition narrative }\end{array}$ \\
\hline & Load & $\begin{array}{l}\text { Institutional load reduces the attention policy } \\
\text { makers can direct to new problems, which creates } \\
\text { niches for frontrunners to develop transition } \\
\text { ideas [56]. }\end{array}$ & $\begin{array}{l}\text { N/A because this occurred before the } \\
\text { CCFPT and the authors' involvement }\end{array}$ \\
\hline & Feedback & $\begin{array}{l}\text { Problem stream feedback can be used for reflexive } \\
\text { transition activities, such as "the monitoring and } \\
\text { evaluation of experiments, agenda, vision, policies } \\
\text { and change processes" [51] (p. 87). }\end{array}$ & $\begin{array}{l}\text { Data from Phoenix Public Transit and } \\
\text { Streets Departments on the state of the } \\
\text { transportation system }\end{array}$ \\
\hline \multirow{5}{*}{ Policy stream } & $\begin{array}{l}\text { VALUE } \\
\text { ACCEPTABILITY }\end{array}$ & $\begin{array}{l}\text { Transitions explicitly focus on "transformative } \\
\text { change, not on adaptive or corrective strategies to } \\
\text { existing policy programs," [51] (p. 81), which is } \\
\text { outside the regime's value acceptability. }\end{array}$ & $\begin{array}{l}\text { Transformative change ( }>\text { USD 30B) in the } \\
\text { regime's value acceptability demonstrates } \\
\text { the potential of linking the approaches. }\end{array}$ \\
\hline & $\begin{array}{l}\text { TECHNICAL } \\
\text { FEASIBILITY }\end{array}$ & $\begin{array}{l}\text { Transitions are less concerned with technical } \\
\text { feasibility than envisioning desirable futures. }\end{array}$ & CCFPT disinterest in autonomous vehicles \\
\hline & $\begin{array}{l}\text { RESOURCE } \\
\text { ADEQUACY }\end{array}$ & $\begin{array}{l}\text { In contrast to focusing on resource adequacy and } \\
\text { costs, transitions focus on envisioning desirable } \\
\text { futures. }\end{array}$ & $\begin{array}{l}\text { Costs and justification on pieces; starting } \\
\text { with pieces on the boards highlighted } \\
\text { desired futures. }\end{array}$ \\
\hline & Network integration & $\begin{array}{l}\text { Facilitation of transition arenas functions for } \\
\text { network integration especially through thoughtful } \\
\text { inclusion [57]. }\end{array}$ & $\begin{array}{l}\text { The CCFPT integrated many } \\
\text { Phoenix networks. }\end{array}$ \\
\hline & Policy community & $\begin{array}{l}\text { The tenet of steering from the "inside" means that } \\
\text { transition arenas include regime insiders, and } \\
\text { policy entrepreneurs, as well as niche frontrunners. }\end{array}$ & $\begin{array}{l}\text { The CCFPT included niche and } \\
\text { regime players. }\end{array}$ \\
\hline \multirow{3}{*}{ Politics stream } & Party ideology & N/A at urban scale & N/A at urban scale \\
\hline & Mood of the public & $\begin{array}{l}\text { The tenet of stakeholder participation and the } \\
\text { guiding principle of inclusivity bring the mood of } \\
\text { the public into the transitions approach. }\end{array}$ & $\begin{array}{l}\text { Citywide engagement efforts reaching } \\
\sim 3500 \text { people. }\end{array}$ \\
\hline & Balance of interests & $\begin{array}{l}\text { The social learning and capacity building principle } \\
\text { of transitions suggests that the balance of interests } \\
\text { can be negotiated with boundary objects, because } \\
\text { they address: "the nature of cooperative work in } \\
\text { the absence of consensus" [33] (p. 604). }\end{array}$ & $\begin{array}{l}\text { The workshop facilitated articulation and } \\
\text { negotiation of the balance of interests, and } \\
\text { attendees reported changed perspectives on } \\
\text { transportation. }\end{array}$ \\
\hline \multirow{2}{*}{$\begin{array}{l}\text { Institutional } \\
\text { context }\end{array}$} & Coupling logic & $\begin{array}{l}\text { Transition arenas offer venues for coupling MSA } \\
\text { streams with "logic or arguments" [4] (p. 16) } \\
\text { grounded in transition principles and practices. }\end{array}$ & $\begin{array}{l}\text { The boundary object workshop structured } \\
\text { the CCFPT's coupling logic. }\end{array}$ \\
\hline & Decision style & $\begin{array}{l}\text { Transitions emphasize diversity and reflective } \\
\text { decision-making in which participants embody } \\
\text { decisions in their subsequent practice. }\end{array}$ & $\begin{array}{l}\text { The workshop was an innovative } \\
\text { decision style }\end{array}$ \\
\hline \multirow{3}{*}{ Policy entrepreneur } & Access & $\begin{array}{l}\text { "Steering from the inside" imbues transition efforts } \\
\text { with access to decision makers. }\end{array}$ & $\begin{array}{l}\text { The makeup of the CCFPT and explicit } \\
\text { connection to mayor and council }\end{array}$ \\
\hline & Resources & $\begin{array}{l}\text { The time and money connected to successful policy } \\
\text { entrepreneurship are also criteria for effective } \\
\text { transition management. Developing transition } \\
\text { visions, piloting experiments, and monitoring } \\
\text { progress require heavy time and resource } \\
\text { investments from the participants in } \\
\text { transition arenas. }\end{array}$ & $\begin{array}{l}\text { The resources required to achieve the vision } \\
\text { articulated by City of Phoenix staff were the } \\
\text { most common point of discussion at } \\
\text { CCFPT meetings. }\end{array}$ \\
\hline & Strategies & $\begin{array}{l}\text { Strategies and strategic planning are key to } \\
\text { achieving transition visions, and strategies are } \\
\text { employed throughout the transitions approach, } \\
\text { from stakeholder selection to designing } \\
\text { transition experiments. }\end{array}$ & $\begin{array}{l}\text { The boundary object workshop for the } \\
\text { transition arena was the strategy to couple } \\
\text { the streams in the CCFPT case. }\end{array}$ \\
\hline
\end{tabular}




\section{Conclusions}

On its own, the MSA describes how policies within the prevailing discourse are realized, often in short-term solutions for persistent problems. For its part, the transitions approach develops forward-thinking options for generational transitions, without necessarily finding the political capital or discursive spaces where those options can be implemented. Yet, there is considerable conceptual complementarity between the MSA and transitions (Table 4). Many aspects are in tune, with divergences instructive, as displayed in the context of the CCFPT process. For example, the premise of the boundary object workshop relied on the guiding principle of diversity from transition management, "a context to reflect, open up, and explore variety" [2] (p. 60), in contrast to the value acceptability of the MSA: "proposals likely to survive conform to existing value constraints" [5] (p. 16). In the other direction, the technical feasibility of the MSA was more prominent for the CCFPT, who did not substantively engage plausible pre-2050 futures (e.g., autonomous vehicles) that could have been addressed in the transportation plan. Similarly, the MSA's resource adequacy was afforded significant discussion at CCFPT meetings (i.e., the costs of potential transportation investments), without similar time spent on visioning activities to explore the desirability of potential futures. These divergences between transitions and the MSA suggest a future research agenda for fostering sustainability transitions by designing for the convergence of policy windows and transition arenas. Our reflections on the CCFPT case lead us to these four future research themes for integrating the MSA with transition management:

(1) How can stakeholder selection and thoughtful inclusion balance the diversity of frontrunner ideas with the value acceptability of the MSA?

(2) How can boundary objects make potential futures salient for policy makers in the present?

(3) How can innovative facilitation strategies help policy makers incorporate desirable futures into considerations of resource adequacy and technical feasibility?

(4) What practices support the intentional design of policy windows in transition arenas?

Beyond research, this article offers some real-world implications and good practice guidelines. One guideline for combining the approaches is that participants in transition arenas can use the MSA as a framework to design policy windows in their arenas. Similarly, this research suggests that policy entrepreneurs attempting to couple the MSA streams and develop policies might benefit from building a transition team, recruiting a transition arena, and adopting the practical framework, tenets, and principles of transitions governance. For both these guidelines, findings from the CCFPT case about where the approaches diverge can help practitioners anticipate and address those gaps.

There is also potential to develop a more dialectical perspective, in which transition processes iterate alongside conventional policy processes. When opportunities arise for exchange, transitions researchers can help build the boundary objects that facilitate planned overlaps of transition efforts and the MSA. This interweaving of approaches over time could, for example, inject the future-orientation of transitions when resource adequacy is a dead-end, creating new space for incremental dynamics to move toward creative futures.

Because the success factors in the CCFPT case emerged in a de-facto transition arena that met the MSA criteria, we suggest that this case could be instructive for future efforts for both transitions and policy development. As more transitions progress and come to fruition, this article might help frame their relationships with policy windows, both supporting post hoc analysis of policy development and suggesting a model for intentionally creating policy windows in transition arenas. A synthetic approach has the potential to help orient transitions to policy development that could contribute to transition goals, and give the MSA the natural venue of transition arenas to "manipulate and couple the streams" [4] (p. 16).

Author Contributions: All authors conceived and designed the research. J.H. assessed the case in the context of the MSA and transitions literatures. Conceptualization, J.H. and Z.Y.; Funding acquisition, E.J. and E.H.; 
Methodology, E.H.; Project administration, J.H.; Supervision, E.J. and E.H.; Visualization, Z.Y.; Writing-original draft, J.H.; Writing-review \& editing, E.J. and E.H.

Funding: This work benefitted from grant funding through the MacArthur Research Network on Opening Governance (grant \# 13-105756-000-USP) and from a grant from the Robert Wood Johnson Foundation, (71995, PI: Hekler).

Acknowledgments: This collaboration was only possible because of extraordinary effort and trust from Megan Neal, Ken Kessler, Melissa Sweinghagen, and Maria Hyatt in Phoenix's Public Transit Department, as well as the Deputy City Manager, Rick Naimark. Special thanks are given to the audio coders, Kalev Kaarna, Holly Smith, and Joshua Uebelherr, to Chul Hyun Park and Joshua Uebelherr for supplying some of the policy development references, and to the students who participated in the courses that helped to inform this work.

Conflicts of Interest: The authors declare no conflict of interest.

\section{Appendix A}

\begin{tabular}{|c|c|c|c|}
\hline & & Plan Elements Worksheet & \\
\hline Category & Card & Back of Card / Specific Details & $\begin{array}{c}\text { Cost } \\
\text { (millions) }\end{array}$ \\
\hline & Bus \& Dial-a-Ride & $\begin{array}{l}\text { Continue currently provided service, maintenance, and federally required dial-a- } \\
\text { ride }\end{array}$ & 11,803 \\
\hline Existing Service & Light Rail \& Dial-A-Ride & $\begin{array}{l}\text { Continue currently provided service, maintenance, and federally required dial-a- } \\
\text { ride }\end{array}$ & 2,142 \\
\hline & Technology upgrades and replacements & Maintain fare collection system, scheduling, GPS tracking in a state of good repair & 270 \\
\hline $\begin{array}{l}\text { Span of Bus } \\
\text { Service (Hrs of }\end{array}$ & Bus matches Light Rail service & Provide service for early morning or late night travelers (would fulfill T2000) & 1,454 \\
\hline Operation) & 24 hour bus service day & Provide service for travel any time of day or night & 1,849 \\
\hline & 15 minute peak frequency on all bus routes & Decreases waiting and improves connectivity on all routes (would fulfill T2000) & 1,818 \\
\hline $\begin{array}{l}\text { Frequency of } \\
\text { Service }\end{array}$ & $\begin{array}{l}15 \text { minute peak frequency on } 60 \% \text { of bus } \\
\text { routes }\end{array}$ & 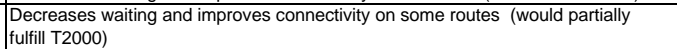 & 1,072 \\
\hline & 30 minute frequency for all bus service & $\begin{array}{l}\text { Higher frequency on routes with greater than } 30 \text { minute frequency, especially } \\
\text { weekend service }\end{array}$ & 755 \\
\hline & $\begin{array}{l}\text { Add bus service to unserved major streets at } \\
15 \text { minute peak frequency }\end{array}$ & Provide connectivity to unserved areas of the city (would fulfill T2000) & 1,606 \\
\hline $\begin{array}{l}\text { Service } \\
\text { Expansion (New }\end{array}$ & $\begin{array}{l}\text { Add bus service to unserved major streets } \\
\text { with } 60 \% \text { of new routes at } 15 \text { minute peak } \\
\text { frequency }\end{array}$ & Provide connectivity to unserved areas of the city (would partially fulfill T2000) & 1,453 \\
\hline $\begin{array}{l}\text { Expansion (New } \\
\text { Bus Service) }\end{array}$ & $\begin{array}{l}\text { Add bus service to unserved major streets at } \\
30 \text { minute peak frequency }\end{array}$ & Provide connectivity to unserved areas of the city (would fulfill T2000) & 1,223 \\
\hline & new RAPID service & Provide connectivity to unserved areas of the city & 80 \\
\hline & new Circulator service & Provide connectivity to local service in unserved neighborhoods & 300 \\
\hline & Capitol/l-10 W Phase 1 Rail & Connect existing rail to the Capitol ( $3 \mathrm{mi})$ & 310 \\
\hline $\begin{array}{l}\text { Approved Light } \\
\text { Rail }\end{array}$ & $\begin{array}{l}\text { Capitol/l-10 W Phase } 2 \text { Rail (have to Phase } \\
\text { 1) }\end{array}$ & Connect the Capitol to the 79th Ave Park-n-Ride ( $8 \mathrm{mi}$ ) & 1,500 \\
\hline & South Central Ave Rail & Connect existing rail to Baseline Road (5 mi) & 850 \\
\hline & Northwest Phase 2 Rail & Connect existing rail to Metrocenter ( $1.7 \mathrm{mi})$ & 250 \\
\hline & Camelback Phase 1 & $\begin{array}{l}\text { Connect 19th Ave to 43rd Ave and Grand Canyon University, the 8th highest } \\
\text { ridership bus route ( } 3 \mathrm{mi} \text { ) }\end{array}$ & 500 \\
\hline & Camelback Phase 2 & $\begin{array}{l}\text { Connect } 43 \text { rd Ave to } 83 r d \text { Ave, WestGate, and the Stadium, 8th highest ridership } \\
\text { bus route }(5 \mathrm{mi})\end{array}$ & 880 \\
\hline & Baseline East & Connect Central Ave to l-10 (5.5 mi) & 1,000 \\
\hline High Capacity & Baseline West & Connect Central Ave to 59th Ave and the potential future $202(8.5 \mathrm{mi})$ & 1,200 \\
\hline Transit (HCT) & Northeast Extension & Connect existing rail to Paradise Valley Mall $(13 \mathrm{mi})$ & 2,600 \\
\hline Corridors: Future & Northwest/ ASU West Extension & Connect Metrocenter Mall to ASU West ( $5.5 \mathrm{mi})$ & 850 \\
\hline $\begin{array}{l}\text { bus rapid transit } \\
\text { (BRT), streetcar, }\end{array}$ & (2) & $\begin{array}{l}\text { Connect existing rail to McDonald Dr, just north of Camelback, a major } \\
\text { employment center ( } 4.5 \mathrm{mi})\end{array}$ & 800 \\
\hline or rail & 24th St & $\begin{array}{l}\text { Connect Biltmore Fashion Park to Baseline Road, the 4th highest ridership bus } \\
\text { route }(10 \mathrm{mi})\end{array}$ & 2,700 \\
\hline & 44th St / Tatum Extension & Connect Shea Blvd to the 101, Mayo Clinic, and Desert Ridge Marketplace (5 mi) & 960 \\
\hline & Downtown Streetcar & $\begin{array}{l}\text { Connect major commercial and employment destinations in downtown Phoenix (5 } \\
\text { miles) }\end{array}$ & 750 \\
\hline & 19th Ave S BRT & Connect existing rail to Baseline $\mathrm{Rd}$, the $3 \mathrm{rd}$ highest ridership bus route $(9.5 \mathrm{mi})$ & 82 \\
\hline Future BRT (Bus & 19th Ave N BRT & Connect existing rail to Happy Valley Rd, 3rd highest ridership bus route ( $10.5 \mathrm{mi})$ & 91 \\
\hline Rapid Transit) & Thomas BRT & Connect 44th St to 91st Ave, the highest ridership bus route ( $18.5 \mathrm{mi})$ & 160 \\
\hline & 35th Ave BRT & Connect Baseline Rd to Happy Valley Rd, 6th highest ridership bus route (20 mi) & 217 \\
\hline & Bell BRT & Connect Scottsdale Rd to $51 \mathrm{st}$ Ave (15 mi) & 121 \\
\hline & All bus stops shaded & Comfort and protection from the heat as desired by passengers & 18 \\
\hline & Customer service technology upgrades & $\begin{array}{l}\begin{array}{l}\text { Reloadable cards (most popular talktransportation.org idea), wifi, digital signs, real- } \\
\text { time data trip planning }\end{array} \\
\end{array}$ & 30 \\
\hline & ADA enhancements & More convenient ADA access, and vehicle and facility improvements & 60 \\
\hline Intrastructure & Security improvements & Increased security & 60 \\
\hline & CNG fuel infrastructure and solar installation & Reduce air pollution and operating costs & 40 \\
\hline & $\begin{array}{l}\text { New Northwest bus operation and } \\
\text { maintenance facility }\end{array}$ & Storage and maintenance necessary for increased bus service. & 60 \\
\hline & Existing transit and all new HCT and bus & All existing transit (473 mi); new HCT ( $60 \mathrm{mi}$ ) and bus (97 mi) & 2930 \\
\hline & $50 \%$ of existing transit and all new HCT & $50 \%$ of existing transit $(236 \mathrm{mi}) ;$ all new HCT $(60 \mathrm{mi})$ & 1478 \\
\hline Complete Streets & $25 \%$ of existing transit and all new HCT & $25 \%$ of existing transit ( $118 \mathrm{mi}$ ); all new HCT (60 mi) & 944 \\
\hline & All new HCT & $60 \mathrm{mi}$ & 410 \\
\hline
\end{tabular}




\section{References}

1. Rotmans, J.; Kemp, R.; van Asselt, M. More evolution than revolution: Transition management in public policy. Foresight 2001, 3, 15-31. [CrossRef]

2. Loorbach, D.; Frantzeskaki, N.; Lijnis Huffenreuter, R. Transition Management: Taking Stock from Governance Experimentation. J. Corp. Citizsh. 2015, 2015, 48-66. [CrossRef]

3. Hölscher, K.; Avelino, F.; Wittmayer, J.M. Empowering Actors in Transition Management in and for Cities. In Co-Creating Sustainable Urban Futures; Springer: Cham, Switzerland, 2018; pp. 131-158.

4. Jones, M.D.; Peterson, H.L.; Pierce, J.J.; Herweg, N.; Bernal, A.; Lamberta Raney, H.; Zahariadis, N. A River Runs Through It: A Multiple Streams Meta-Review. Policy Stud. J. 2016, 44, 13-36. [CrossRef]

5. Cairney, P.; Jones, M.D. Kingdon's Multiple Streams Approach: What Is the Empirical Impact of this Universal Theory? Policy Stud. J. 2016, 44, 37-58. [CrossRef]

6. Hermansen, E.A.T. Policy window entrepreneurship: The backstage of the world's largest REDD+ initiative. Environ. Polit. 2015, 24, 932-950. [CrossRef]

7. Jhagroe, S.; Loorbach, D. See no evil, hear no evil: The democratic potential of transition management. Environ. Innov. Soc. Transit. 2015, 15, 65-83. [CrossRef]

8. Frank, L.D.; Sallis, J.F.; Conway, T.L.; Chapman, J.E.; Saelens, B.E.; Bachman, W. Many pathways from land use to health. J. Am. Plan. Assoc. 2006, 72, 75-87. [CrossRef]

9. Newman, P.; Kenworthy, J. Sustainability and Cities: Overcoming Automobile Dependence; Island Press: Washington, DC, USA, 1999.

10. Pucher, J.; Dijkstra, L. Promoting Safe Walking and Cycling to Improve Public Health Walking and Cycling: The MOST sustainable transport modes. Am. J. Public Health 2003, 93, 1509-1516. [CrossRef] [PubMed]

11. Lindsay, G.; Macmillan, A.; Woodward, A. Moving urban trips from cars to bicycles: Impact on health and emissions. Aust. N. Z. J. Public Health 2011, 35, 54-60. [CrossRef] [PubMed]

12. Gilens, M.; Page, B.I. Testing Theories of American Politics: Elites, Interest Groups, and Average Citizens. Perspect. Polit. 2014, 12, 564-581. [CrossRef]

13. Fainstein, S.S. Competitiveness, Cohesion, and Governance: Their Implications for Social Justice. Int. J. Urban Reg. Res. 2001, 25, 884-888. [CrossRef]

14. Barbosa, A.E.; Fernandes, J.N.; David, L.M. Key issues for sustainable urban stormwater management. Water Res. 2012, 46, 6787-6798. [CrossRef] [PubMed]

15. Conway, T.M.; Shakeel, T.; Atallah, J. Community groups and urban forestry activity: Drivers of uneven canopy cover? Landsc. Urban Plan. 2011, 101, 321-329. [CrossRef]

16. Elsom, D. Smog Alert: Managing Urban Air Quality; Routledge: Abingdon, UK, 2014.

17. Frantzeskaki, N.; Hölscher, K.; Bach, M.; Avelino, F. Co-Creating Sustainable Urban Futures; Future City; Springer International Publishing: Cham, Switzerland, 2018; Volume 11, ISBN 978-3-319-69271-5.

18. Kemp, R.; Loorbach, D. Governance for Sustainability through Transition Management. In Proceedings of the 2003 Open Meeting of the Human Dimensions of Global Environmental Change Research Community, Montreal, QC, Canada, 16-19 October 2003.

19. Rotmans, J.; Kemp, R. Managing Societal Transitions: Dilemmas and Uncertainties: The Dutch Energy Case Study; OECD Workshop on the Benefits of Climate Policy: Paris, France, 2003.

20. Loorbach, D.; Rotmans, J. The practice of transition management: Examples and lessons from four distinct cases. Futures 2010, 42, 237-246. [CrossRef]

21. Frantzeskaki, N.; Wittmayer, J.; Loorbach, D. The role of partnerships in "realising" urban sustainability in Rotterdam's City Ports Area, the Netherlands. J. Clean. Prod. 2014, 65, 406-417. [CrossRef]

22. Nevens, F.; Frantzeskaki, N.; Gorissen, L.; Loorbach, D. Urban Transition Labs: Co-creating transformative action for sustainable cities. J. Clean. Prod. 2013, 50, 111-122. [CrossRef]

23. van Buuren, A.; Loorbach, D. Policy innovation in isolation? Conditions for policy renewal by transition arenas and pilot projects. Public Manag. Rev. 2009, 11, 375-392. [CrossRef]

24. Kern, F.; Howlett, M. Implementing transition management as policy reforms: A case study of the Dutch energy sector. Policy Sci. 2009, 42, 391-408. [CrossRef]

25. Nooteboom, S.; Teisman, G. Sustainable development: Impact assessment in the age of networking. J. Environ. Policy Plan. 2003, 5, 285-309. [CrossRef] 
26. Scholten, P. Daring decisions and representative municipal democracy: An exploration within the new river management in the Netherlands. Innov. J. 2009, 14, 1-15.

27. Paredis, E.; Block, T. The Art of Coupling: Multiple Streams and Policy Entrepreneurship in Flemish Transition Governance Processes; Policy Research Centre TRADO: Ghent, Belgium, 2013.

28. Bettini, Y.; Head, B. Governance Structures and Strategies to Support Innovation and Adaptability; Cooperative Research Centre for Water Sensitive Cities: Melbourne, Australia, 2016.

29. MacRae, R.; Winfield, M. A little regulatory pluralism with your counter-hegemonic advocacy? Blending analytical frames to construct joined-up food policy in Canada. Can. Food Stud. 2016, 3, 140-194.

30. Van Poeck, K.; Læssøe, J.; Block, T. An exploration of sustainability change agents as facilitators of nonformal learning: Mapping a moving and intertwined landscape. Ecol. Soc. 2017, 22, 33. [CrossRef]

31. Noboa, E.; Upham, P. Energy policy and transdisciplinary transition management arenas in illiberal democracies: A conceptual framework. Energy Res. Soc. Sci. 2018, 46, 114-124. [CrossRef]

32. Star, S.L.; Griesemer, J.R. Institutional Ecology, 'Translations' and Boundary Objects: Amateurs and Professionals in Berkeley's Museum of Vertebrate Zoology, 1907-39. Soc. Stud. Sci. 1989, 19, 387-420. [CrossRef]

33. Leigh Star, S. This is Not a Boundary Object: Reflections on the Origin of a Concept. Sci. Technol. Hum. Values 2010, 35, 601-617. [CrossRef]

34. Golub, A.; Guhathakurta, S.; Sollapuram, B. Spatial and Temporal Capitalization Effects of Light Rail in Phoenix: From Conception, Planning, and Construction to Operation. J. Plan. Educ. Res. 2012, 32, 415-429. [CrossRef]

35. Transportation Review Committee. Citizens Committee on the Future of Phoenix Transportation; Transportation Review Committee: Phoenix, AZ, USA, 2015.

36. Neal, M. Citizens Committee on the Future of Phoenix Transportation Packet; City of Phoenix: Phoenix, AZ, USA, 2014.

37. City of Phoenix. Citizens Committee on the Future of Phoenix Transportation 14.09.18 Meeting Minutes; City of Phoenix: Phoenix, AZ, USA, 2014.

38. City of Phoenix. No Citizens Committee on the Future of Phoenix Transportation 14.11.22 Meeting Minutes; City of Phoenix: Phoenix, AZ, USA, 2014.

39. City of Phoenix. Citizens Committee on the Future of Phoenix Transportation 14.10.08 Meeting Minutes; City of Phoenix: Phoenix, AZ, USA, 2014.

40. Feldman, M.S.; Quick, K.S. Generating resources and energizing frameworks through inclusive public management. Int. Public Manag. J. 2009, 12, 137-171. [CrossRef]

41. Maguire, M. Methods to support human-centred design. Int. J. Hum. Comput. Stud. 2001, 55, 587-634. [CrossRef]

42. Hekler, E.B.; Klasnja, P.; Riley, W.T.; Buman, M.P.; Huberty, J.; Rivera, D.E.; Martin, C.A. Agile science: Creating useful products for behavior change in the real world. Transl. Behav. Med. 2016, 1-12. [CrossRef] [PubMed]

43. Snyder, C. Paper Prototyping: The Fast and Easy Way to Design and Refine User Interfaces; Morgan Kaufmann: Burlington, MA, USA, 2003; ISBN 9781558608702.

44. Simonsen, J.; Robertson, T. Routledge International Handbook of Participatory Design; Routledge: Abingdon, UK, 2012; ISBN 9780415694407.

45. Johnston, E.W.; Hansen, D.L. Design lessons for smart governance infrastructures. In Transforming American Governance: Rebooting the Public Square; Routledge: Abingdon, UK, 2011; Volume 1, pp. 197-212. ISBN 978-1-317-45335-2.

46. Cash, D.; Clark, W.C.; Alcock, F.; Dickson, N.; Eckley, N.; Jäger, J. Salience, Credibility, Legitimacy and Boundaries: Linking Research, Assessment and Decision Making. SSRN Electron. J. 2002, 25. [CrossRef]

47. Schwartz, B. The Paradox of Choice. In Positive Psychology in Practice: Promoting Human Flourishing in Work, Health, Education, and Everyday Life, 2nd ed.; John Wiley \& Sons: Hoboken, NJ, USA, 2015; pp. 121-138. ISBN 9781118996874.

48. Braun, V.; Clarke, V. Using thematic analysis in psychology. Qual. Res. Psychol. 2006, 3, 77-101. [CrossRef]

49. Guston, D.H. Boundary Organizations in Environmental Policy and Science: An Introduction. Sci. Technol. Human. Values 2001, 26, 399-408. [CrossRef] 
50. Roorda, C.; Wittmayer, J.; Henneman, P.; van Steenbergen, F.; Frantzeskaki, N.; Loorbach, D. Transition Management in the Urban Context: Guidance Manual; Drift Erasmus University Rotterdam: Rotterdam, The Netherlands, 2014.

51. Wittmayer, J.M.; van Steenbergen, F.; Frantzeskaki, N.; Bach, M. Transition Management: Guiding Principles and Applications. In Co-Creating Sustainable Urban Futures; Springer: Cham, Switzerland, 2018; pp. 81-101.

52. Frantzeskaki, N.; Bach, M.; Mguni, P. Understanding the Urban Context and Its Challenges. In Co-Creating Sustainable Urban Futures; Springer: Cham, Switzerland, 2018; pp. 43-61.

53. City of Phoenix. Citizens Committee on the Future of Phoenix Transportation 14.11.05 Meeting Minutes; City of Phoenix: Phoenix, AZ, USA, 2014.

54. Peters, M. Citizens Committee on the Future of Phoenix Transportation 15.02.27 Recommendation; City of Phoenix: Phoenix, AZ, USA, 2015.

55. City of Phoenix. Citizens Committee on the Future of Phoenix Transportation 14.08.26 Meeting Minutes; City of Phoenix: Phoenix, AZ, USA, 2014.

56. Rotmans, J.; Loorbach, D. Complexity and transition management. J. Ind. Ecol. 2009, 13, 184-196. [CrossRef]

57. Johnston, E.W.; Hicks, D.; Nan, N.; Auer, J.C. Managing the inclusion process in collaborative governance. J. Public Adm. Res. Theory 2011, 21, 699-721. [CrossRef]

(c) 2018 by the authors. Licensee MDPI, Basel, Switzerland. This article is an open access article distributed under the terms and conditions of the Creative Commons Attribution (CC BY) license (http:/ / creativecommons.org/licenses/by/4.0/). 